\title{
SPECULAR MICROSCOPY OF THE ANTERIOR INTRAOCULAR LENS SURFACE
}

\author{
S. M. SHAH, D. J. SPALTON and M. KERR MUIR \\ London
}

\begin{abstract}
SUMMARY
Until recently the cytological assessment of the intraocular lens (IOL) surface was only possible using in vitro cytopathological techniques on explanted lenses or in animal models. Specular microscopy provides an in vivo method for the observation of the IOL surface at high magnification. We have used this technique to examine the IOL surface of 27 normal pseudophakic eyes in the first 3 months following implantation. Cellular deposits consisting of small and giant inflammatory cells were found to be a normal occurrence in otherwise clinically successful cataract surgery. It was also possible to visualise the anterior capsule and its attachment to the IOL surface, an amorphous surface membrane, pigment, surface contaminants (starch granules and fibres), and the markings caused by instrumentation at the time of implantation. The technique of IOL surface specular microscopy therefore provides a useful method for the visualisation of the IOL surface and the cytological reaction that occurs there, and thus allows an assessment of IOL biocompatibility.
\end{abstract}

Specular microsopy has been used as a standard technique for many years in the study of corneal pathophysiology ${ }^{1}$ following its original description by Vogt. ${ }^{2}$ More recently, Ohara $^{3}$ and Wenzel ${ }^{4}$ have adapted the specular microscope to study the cells deposited on the intraocular lens (IOL) surface and this has been used in several studies as an in vivo technique for the assessment of the biocompatibility of IOL materials. ${ }^{5,6}$ This paper describes our use of this technique in a group of pseudophakic patients and reports on the variety of deposits found on the IOL surface.

\section{MATERIALS AND METHODS}

We used a wide-field Keeler-Konan specular microscope. A low-power $(\times 22)$ applanation dipping cone was fitted to provide sufficient depth of field to focus the IOL surface. Following maximal pupillary dilatation topical local UK.

From: Department of Ophthalmology, St Thomas' Hospital, London,

Correspondence to: Mr. D. J. Spalton, The Medical Eye Unit, St Thomas' Hospital, Lambeth Palace Road, London SE1 7EH, UK. anaesthetic was instilled, the cone wetted with saline and the cornea applanated. The cone was advanced until the IOL surface was in focus. The patient was then asked to direct the gaze until a specular reflex of the IOL was obtained. The IOL surface was scanned and features of interest photographed using 200 ASA slide film (Kodak Ektachrome) at maximal illumination and flash settings.

To aid further interpretation and orientation of these highly magnified photographs a drawing of the IOL surface was also made at the same time. Calibration was performed by photographing an IOL dialling hole of known diameter. With experience it was also possible to obtain non-contact photographs by removing the cone and advancing the microscope until the IOL surface specular reflex could be visualised. This was an advantage in the immediate post-operative period and in patients who were unable to tolerate applanation, although in our experience the quality of the photographs was less good.

Twenty-seven eyes of 26 patients (mean age 68.6 years, range $49-80$ years, 10 men) admitted for routine cataract surgery were photographed at 1 and 3 months post-operatively to evaluate the technique. The informed consent of each patient was obtained after the nature of the investigation had been fully explained. All patients were otherwise free of ocular disease. They were all systemically well and in particular on no topical or systemic antiinflammatory medication. All surgery was performed by a single surgeon using a standardised endocapsular surgical technique. Following surgery all patients received the same post-operative medication (topical dexamethasone $0.1 \%$ and neomycin $0.35 \%$ four times daily for 1 week reducing to twice daily for a further 3 weeks) unless otherwise clinically indicated.

\section{RESULTS}

\section{Calibration}

A specular photograph of an IOL dialling hole with a diameter of $400 \mu \mathrm{m}$ is shown in Fig. 1. Using this it was possible to calibrate the system and also to calculate and confirm that the magnification at the film plane was $\times 22$. 


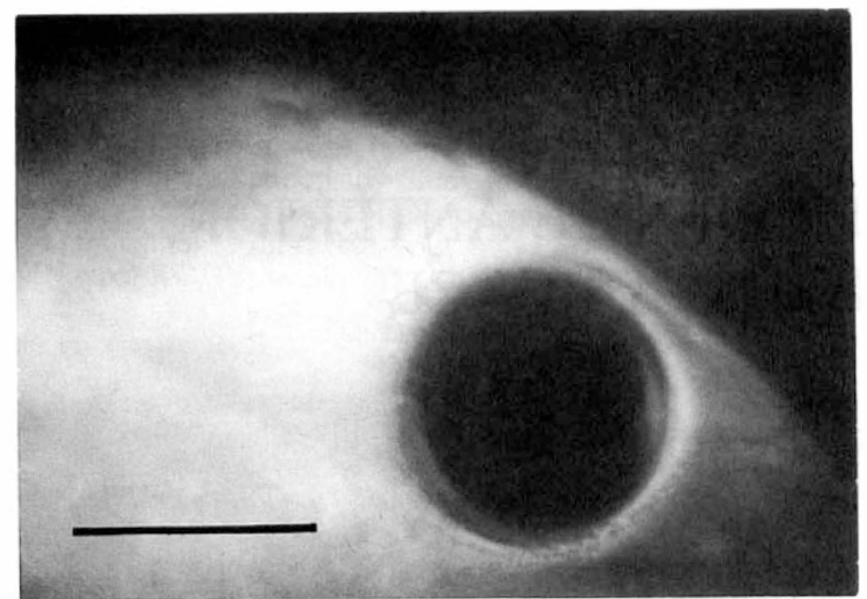

Fig. 1. The dialling hole of an intraocular lens viewed through the specular microscope. Magnification at the film plane $\times 22$. Scale bar represents $400 \mu \mathrm{m}$.

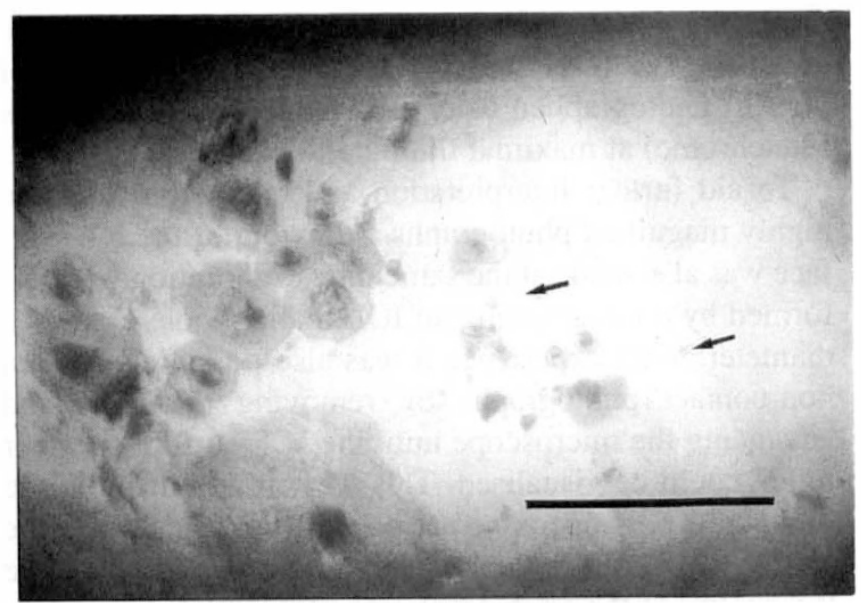

Fig. 3. Giant cells and a proteinaceous membrane on the surface of an intraocular lens. The membrane can be seen by the linear break in its surface (arrows). Scale bar represents $400 \mu \mathrm{m}$.

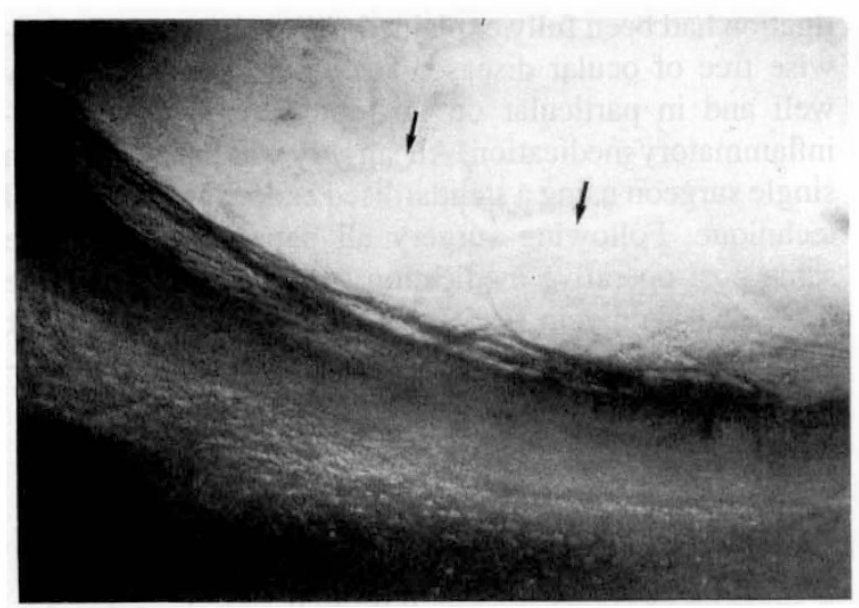

Fig. 5. Black and white photography of Newton's ring formation (arrows) by a proteinaceous membrane on the surface of an intraocular lens. These coloured rings are due to the separation of the incident white light into its primary colours by a surface layer with a thickness less than the wavelength of the incident light.

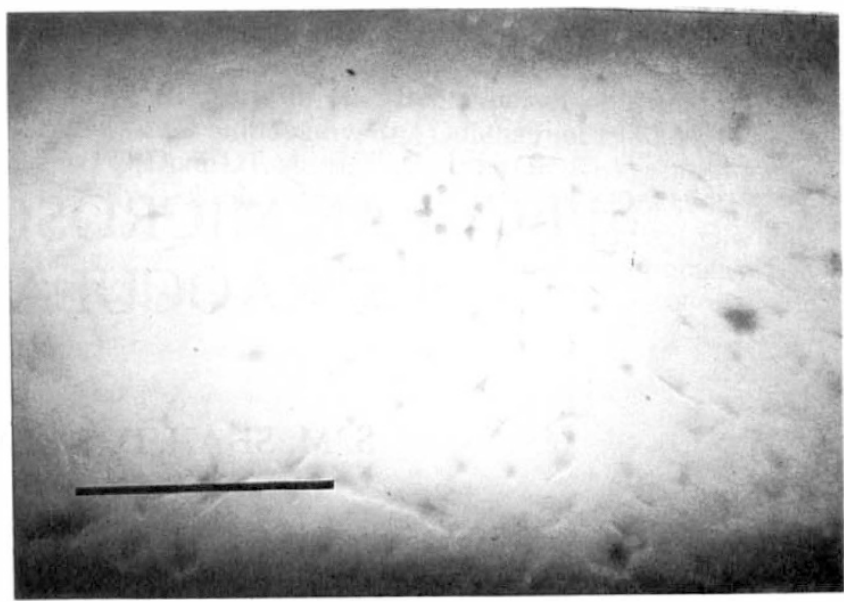

Fig. 2. Cellular deposits on an intraocular lens surface showing small fibroblast-like cells and small round cells. Scale bar represents $400 \mu \mathrm{m}$.

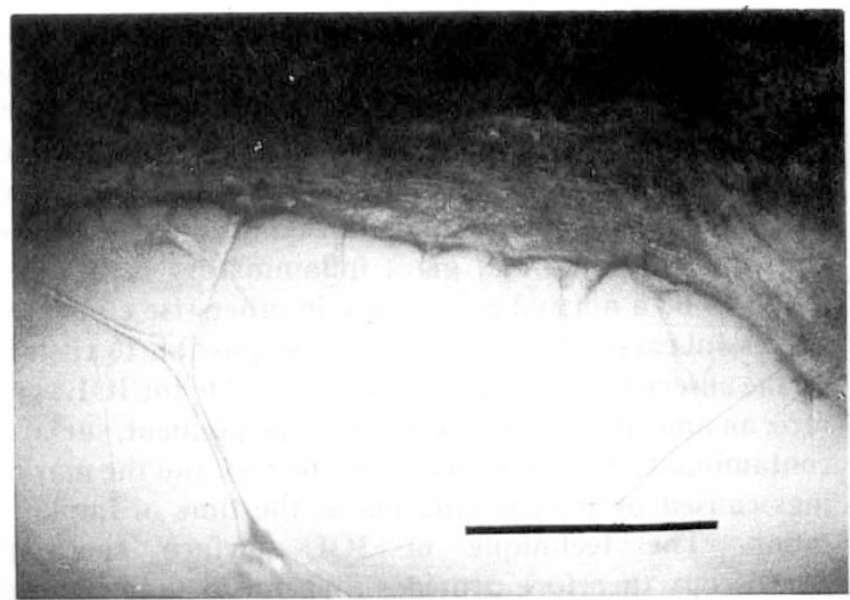

Fig. 4. The attachment of the edge of the anterior capsule to the intraocular lens surface as viev'ed with the specular microscope, demonstrating migration of a cell presumably derived from the anterior lens epithelium onto the surface of the implant. Scale bar represents $400 \mu \mathrm{m}$.

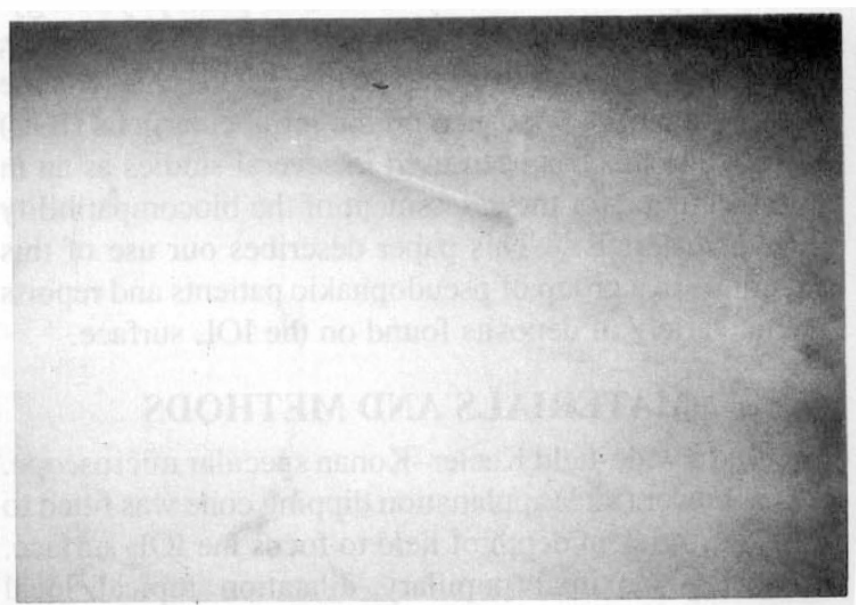

Fig. 6. Surface contaminants on intraocular lens surfaces: fibres inadvertently introduced at the time of implantation. 


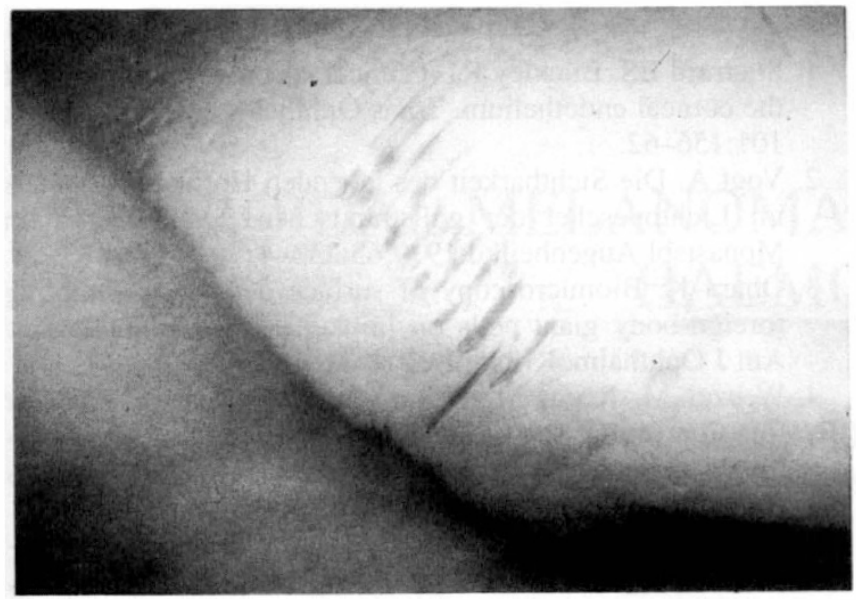

Fig. 7. Linear scratches and markings on the surface of an intraocular lens due to handling of the lens at the time of implantation. These are not associated with any cellular reaction.

\section{Cellular Deposits}

Inflammatory Cells. Cells were visualised on the majority of IOLs and could be divided on the basis of size into two main populations: small and giant cells. Small cells could be further subdivided on the basis of morphology into spindle-shaped fibroblast-like cells (length up to $130 \mu \mathrm{m}$ ) and round cells (diameter 10-20 $\mu \mathrm{m}$ ) (Fig. 2). These two types of small cells were usually found together and tended to be diffusely distributed either over the entire IOL surface or in the vicinity of giant cells.

Giant cells could also be divided on the basis of size and morphology into two types: the epithelioid cells and true giant cells (Fig. 3). Epithelioid cells were smaller (diameter usually about $40-60 \mu \mathrm{m}$ ), round and had a central intracellular pigmented region, whereas true giant cells were much larger (up to $750 \mu \mathrm{m}$ ), usually irregular in shape, and had a more asymmetrical distribution of intracellular pigment. Giant cells were usually found clumped together, often at the periphery of the IOL adjacent to the anterior capsular edge or in the vicinity of posterior synechiae.

Anterior Capsule. Using the technique it was possible to visualise clearly the anterior capsule in varying degrees of opacification and its attachment to the IOL surface. In a few patients there was evidence of apparent proliferation and migration of cells from the cut edge of the anterior capsule onto the IOL surface (Fig. 4).

\section{Non-cellular Debris}

Pigment. Pigment granules presumably derived from the iris pigment epithelium were frequently seen and ranged from a few specks to large clumps.

Surface Membrane. In several patients it was possible to visualise a layer of amorphous acellular material covering the IOL surface. This layer was often clearly seen due to the presence of a break or gap in its surface (Fig. 3) or to the presence of Newton's rings (Fig. 5). These coloured rings were seen in several patients, either alone on the IOL surface implying the presence of a thin amorphous surface layer, or as part of a cell deposit where the cell was thinnest. They are due to the separation of the incident light into its primary colours by a surface layer about $1 \mu \mathrm{m}$ in thickness.

Surface Debris. A variety of coincidental contaminants were found on IOL surfaces. These included small white refractile deposits which were presumably starch granules, and fibres inadvertently introduced at the time of implantation (Fig. 6).

IOL Surface Damage. Linear scratches and surface markings on the IOL surface as a result of instrumentation of the IOL were seen in several patients, but these were not specifically related to cellular, protein or pigment deposition (Fig. 7).

\section{DISCUSSION}

In this study the technique of IOL surface specular microscopy allowed visualisation and photography of the anterior IOL surface and in vivo characterisation of surface deposits and cells. Although the technique does require experience and practice, particularly in localisation of the specular reflex, it was relatively straightforward to perform and was well tolerated. With experience of the specular microscope and knowledge of the characteristics of IOL surface deposits we found it was also possible to recognise these deposits with high-power slit-lamp biomicroscopy using specular reflection.

There has recently been considerable interest in this aspect of IOL surface cytology as a method of assessing the biocompatibility of IOL materials and the effect of surface modification. ${ }^{5.6}$ Cellular deposits were found to be a consistent finding on the majority of IOL surfaces examined, despite the fact that the eyes studied were normal except for cataract and had uncomplicated surgery with an uneventful recovery and clinically successful outcome. There were two main types of inflammatory cells: small inflammatory cells consisting of small round cells and spindle-shaped fibroblast-like cells, and giant cells consisting of large round or oval cells (epithelioid cells) and even larger round or map-shaped cells (true giant cells). Many IOLs had an amorphous membrane on their surface.

These findings confirm the previous in vivo specular microscope work of Ohara, ${ }^{3}$ Wenzel ${ }^{4,7}$ and Yamanaka, ${ }^{6}$ and the results of earlier cytopathological ${ }^{8-10}$ and electron microscopic ${ }^{11,12}$ studies using explanted IOLs.

Until recently the assessment of the cytological reaction on IOL surfaces was only possible in cytopathological studies on explanted IOLs. Wolter ${ }^{8}$ introduced the technique of lens implant cytology in 1982 and, in a study of 211 explanted IOLs, reported that they all had cellular surface deposits and an eosinophilic proteinaceous membrane (Wolter's membrane) that encapsulated the IOL. ${ }^{9}$ He identified three major inflammatory cell types: small spindle-shaped and bipolar cells (fibroblast-like cells), larger oval or round epithelioid cells, and huge multinucleated foreign body giant cells. ${ }^{9.10}$ Wolter proposed that these cells were derived from macrophages and sug- 
gested that this inflammatory reaction and encapsulation was the result of a foreign body response that prevented any further reaction and led to intraocular tolerance. The presence of these cell types and a surface membrane has subsequently been confirmed by others using light, scanning and transmission electron microscopy, ${ }^{11,12}$

The use of the specular microscope for the in vivo visualisation of the IOL surface was first described by Ohara $^{3}$ in 1985 . Using a technique similar to the one described in this study he was able to demonstrate the presence of inflammatory cells on IOL surfaces and to confirm Wolter's observations on explanted IOLs. Similar results were also found by Wenzel et al. ${ }^{4}$ using the Leitz 'Biophthal' specular microscope and a non-contact technique and by Yamanaka et al..$^{6}$ using the Keeler-Konan specular microscope.

Using this technique we were also able to visualise the anterior capsule following IOL implantation, in particular its opacification and cellular proliferation, and to document the presence of contaminating surface debris and damage to the IOL as a result of instrumentation. The presence of inorganic contaminants on IOL surfaces following manufacture and packaging has been previously described by Ratner ${ }^{13}$ using scanning electron microscopy, energy dispersive X-ray analysis and electron spectroscopy; the possibility of contamination of IOL surfaces by powder from surgical gloves has been discussed by Bene and Kranias ${ }^{14}$ but not demonstrated in vivo.

The technique of specular microscopy of the anterior IOL surface therefore provides a convenient in vivo method for the post-operative assessment of the effect of surgical technique, instrumentation and surface contamination, and for the evaluation of IOL materials and biocompatibility.

Key words: Biocompatibility, Cellular deposits, Intraocular lens surface, Newton's rings, Specular microscopy.

\section{REFERENCES}

1. Sherrard ES, Buckley RJ. Clinical specular microscopy of the corneal endothelium. Trans Ophthalmol Soc UK 1981; 101:156-62.

2. Vogt A. Die Sichtbarkeit des lebenden Hornhautendothels im Lichtbueschel der gullstrandschen Spaltlampe. Klin Monastsbl Augenheilkd 1919;63:233-4.

3. Ohara K. Biomicroscopy of surface deposits resembling foreign-body giant cells on implanted intraocular lenses. Am J Ophthalmol 1985;99:304-11.

4. Wenzel M, Reem M, Heenze M, Boecking A. Cellular invasion on the surface of intraocular lenses. In vivo cytological observations following lens implantation. Graefe's Arch Clin Exp Ophthalmol 1988;226:449-54.

5. Ygge J, Wenzel M, Philipson B, Fagerholm P. Cellular reactions on heparin surface modified versus regular PMMA lenses during the first post-operative month: a doublemasked and randomised study using specular microphotography. Ophthalmology 1990;97:1216-23.

6. Yamanaka A, Kazusa R, Takayama S. Cells on the various kinds of intraocular lens implants. Eur J Implant Ref Surg 1989;1:15-7.

7. Wenzel YM, Brab M, Reem M, Boecking A. Inflammatory reactions against intraocular lenses: in vivo cytological differentiation. Eur J Implant Ref Surg 1989;1:89-94.

8. Wolter JR. Lens implant cytology. Ophthalmic Surg 1982; 13:939-42.

9. Wolter JR. Cytopathology of intraocular lens implantation. Ophthalmology 1985;92:135-41.

10. Wolter JR. Foreign body giant cells on intraocular lens implants. Graefe's Arch Clin Exp Ophthalmol 1982;219: 103-11.

11. Sievers $\mathrm{H}$ von $\mathrm{D}$. Foreign body reaction against intraocular lenses. Am J Ophthalmol 1984;94:743.

12. Leonard TJK, Grierson I, Fison PN, Spalton DJ, et al. Life on implants. Trans Ophthalmol Soc UK 1983;103:165-73.

13. Ratner BD. Analysis of surface contaminants on intraocular lenses. Arch Ophthalmol 1983;101:1434-8.

14. Bene C, Kranias G. Possible intraocular lens contamination by surgical glove powder. Ophthalmic Surg 1986;17:1. 